\title{
Multi-Walled Carbon Nanotubes/Chitosan Nanocomposite from Oil Palm Shell as Adsorbent to Reduce Levels of Metal Hg Ion in Liquid Waste Gold Mine
}

\author{
Masdania Zurairah Siregar ${ }^{1}$, Ahmad Hafizullah Ritonga ${ }^{2}$ \\ ${ }^{1,2}$ Faculty of Engineering/University of Al-Azhar, Medan, Indonesia \\ ${ }^{1}$ zurairahmasdania@gmail.com, ${ }^{2}$ ahmad.hafizullah.ritonga@gmail.com
}

\begin{abstract}
Multi-Walled Carbon Nanotubes (MWCNT)/chitosan nanocomposite can be produced by mixing the MWCNT from oil palm shells with chitosan through sonication process by adding glutaraldehyde 2,5\% as a crosslinking. MWCNT made by using activated carbon resulting from the processing of solid waste oil palm shells through pyrolysis CVD method with a heating temperature of $950{ }^{\circ} C$. The results obtained were characterized by XRD showed that nano-sized particles with an average particle size of $131.0585 \mathrm{~nm}$, FTIR test results indicated a shift in the $C=C$ bonds, and SEM tests showed that the long tubular morphology MWCNT. MWCNT / chitosan nanocomposite applied as adsorbent in wastewater gold mine to adsorb ions Hg were analyzed using ICP-AES. Results of the analysis showed adsorption average above $96 \%$ with optimum contact time of 25 minutes and a flow rate of $5 \mathrm{~mL} / \mathrm{min}$.
\end{abstract}

Keywords: MWCNT, chitosan, glutaraldehyde, nanocomposite, adsorption.

\section{INTRODUCTION}

Mining business in Indonesia until today is still regarded by most people as one of the causes of environmental degradation and pollution, such as one liquid waste from a gold mine. Liquid waste from gold mines contain highly hazardous metals such as mercury. Generally mining often dispose of their waste directly into the river without any prior screening process so that's it is triggering environmental pollution. There are many ways that can be done to overcome the liquid waste from gold mines, namely the use of absorbent material to reduce levels of metals contained in the wastewater, such as activated carbon, chitosan, including modification of the adsorbents have also been made in improving the quality of the adsorbent. Modifications can be done to make a better adsorbent is by using oil palm shell and turn it into activated carbon, and then used as a support medium for growing carbon nanotubes (CNTs). CNT is a carbon nano-sized and shaped long tubes, which serves as the adsorbent with absorbency considered quite good.

Gold mining in Indonesia, generally still has a problem in waste management, where most people are still using the amalgamation method is a method that uses mercury $(\mathrm{Hg})$ as a medium to bind gold. Waste processing and refining gold results are often dumped directly into the river. It is certainly cause environmental damage and pollution. The most dangerous metal ions in the waste is Mercury $(\mathrm{Hg})$. Mercury is not only annoying health conditions but it can also lead to death.

The liquid waste before disposal must go through a screening process so it does not pollute the environment. To overcome these problems is to use the adsorbent in order to reduce levels of the metals contained in the liquid waste, especially metallic mercury. Generally, the adsorbent that is often used is activated carbon, chitosan, and modification of the two adsorbents also been made in improving the quality of the absorbent material. The use of an adsorbent for liquid waste, must use materials that are cheap and easy to obtain, and the method of manufacture is simple.

Oil palm areas in Indonesia is quite extensive. Oil palm can produce CPO, also produce wastes that can be used as empty fruit bunches, coir and oil palm shells. So far, the utilization of solid waste oil palm shells has not been maximized. Alternative is to turn it into active carbon, then activated carbon is used as support for growing CNT. CNT obtained can be used as an adsorbent for the ability of the power adsorbed fairly well. CNT surface area becomes even greater because the nano-sized tubular. 
The use of waste palm shells, based on some other studies such as Atyaforza (2012), which uses acetylene gas in the manufacture of MWCNT by CCVD method, and then comparing the use of catalysts Fe and Co to the morphological properties of CNTs produced. Najma (2012) which made MWCNT from banana peel waste by converting it first into activated carbon, and then converted into a CNT with the methods used pyrolysis-CVD. Gang-Yu (2014) compared the absorption ability of the two adsorbents both SWCNT and MWCNT against organic materials, such as pesticides, dyes, phenols, pharmaceuticals, aromatics, amines, and toxic organic material in the wastewater, test results show that SWCNT has excess can absorb a lot of organic material, but its weakness is expensive in the manufacturing process, while MWCNT is cheaper to make, but it has a smaller absorption ability, and he said it is still be handled by doing modifications to the MWCNT into composite materials.

Use of chitosan as composite materials is one of the technologies that can be considered. In addition, research has also been carried out. Manufacture of chitosan material was easily available and relatively low cost in processing. Chitosan material can also be made from crab shell waste. Some research on CNT-chitosan have been made, among others, Shieh et al (2013) which makes CNTchitosan nanocomposite using different acid solution is acetic acid, hydrochloric acid, and citric acid, to dissolve the chitosan and further mixed with fCNT CNT (CNT-COOH) any variation of the acid solution. Zurairah (2015) uses waste palm shells and crab shell waste (Tachypleus gigas) for the preparation and characterization of CNT-chitosan nanocomposite with the composition ratio (1:3) through the methods of sonication. Salam et al (2011) have added glutaraldehyde used as agents crosslinking the MWCNT-chitosan nanocomposite, and the result was applied as adsorbent with reviewing the influence of increased temperature, mass difference adsorbent, and the speed of the flow rate to attract heavy metals such as $\mathrm{Co}, \mathrm{Cd}, \mathrm{Zn}$ and Ni. From these studies, it is to obtain the maximum results in the adsorption levels of $\mathrm{Hg}$ in gold mining wastewater, it is necessary to modify the adsorbent that is by mixing MWCNT processed waste palm shells, chitosan and glutaraldehyde through sonication methods.

Based on the description, this research discusses the Multi-Walled Carbon Nanotubes / Chitosan nanocomposite of oil palm shells as adsorbent to reduce levels of $\mathrm{Hg}$ in the waste liquid gold mine. This study aims to determine the effectiveness of the use of MWCNT - chitosan nanocomposite as an adsorbent for reducing the $\mathrm{Hg}$ from liquid waste gold mine.

\section{METHODS}

\subsection{Preparation of MWCNT Of Activated Carbon Oil Palm Shell}

Oil palm shells were clean dried in an oven. $500 \mathrm{~g}$ of dry oil palm shells are taken to carbonized $(\mathrm{t}=3$ $\left.\mathrm{h}, \mathrm{T} 400{ }^{\circ} \mathrm{C}\right)$, the result is added $\mathrm{H}_{3} \mathrm{PO}_{4} 7 \%(1: 10)$ while stirring, then filtered and dried in an oven $(\mathrm{t}=$ $24 \mathrm{~h})$. Afterthat, put in a furnace $\left(\mathrm{t}=3 \mathrm{~h}, \mathrm{~T} 600{ }^{\circ} \mathrm{C}\right)$, then successively washed with $5 \mathrm{~N} \mathrm{HCl,hot}$ distilled water until $\mathrm{pH}$ neutral,and cold distilled water.Then dried in an oven, crushed, and filtered.Results obtained in the form of activated carbon, and then taken $100 \mathrm{~g}$, calcined $(\mathrm{t}=4 \mathrm{~h}, \mathrm{~T}$ $\left.400{ }^{\circ} \mathrm{C}\right)$. Created impregnation of activated carbon $(100 \mathrm{~g}$ : $1000 \mathrm{ml})$ solution of $\mathrm{Fe}$ from $\mathrm{Fe}$ $\left(\mathrm{NO}_{3}\right)_{3} .9 \mathrm{H}_{2} \mathrm{O}$ are dissolved with 0.09 Macetone, sonicated $\left(\mathrm{T} 70{ }^{\circ} \mathrm{C}\right)$ until the solvent evaporated exhausted, dried in an oven. Results obtained calcined in a quartz reactor which has been modified by connecting three gas cylinders. Then $\mathrm{N}_{2}$ gas on the tube I streamed $\left(\mathrm{v}=50 \mathrm{~mL} / \mathrm{min}, \mathrm{t}=4 \mathrm{~h}, \mathrm{~T} 500{ }^{\circ} \mathrm{C}\right)$, and then reduced with $\mathrm{H}_{2}$ gas in the tube II $\left(\mathrm{v}=70 \mathrm{~mL} / \mathrm{min}, \mathrm{t}=4 \mathrm{~h}, \mathrm{~T} 700{ }^{\circ} \mathrm{C}\right)$. Furthermore, the temperature is raised to $950{ }^{\circ} \mathrm{C}$ while $\mathrm{N}_{2}$ gas flowed slowly up to $200 \mathrm{~mL} / \mathrm{min}$, methane gas in the tube III streamed $(v=100 \mathrm{~mL} / \mathrm{min})$ simultaneously. The results obtained were characterized by FTIR, and SEM.

\subsection{Preparation and Characterization of MWCNT/Chitosan Nanocomposite}

$2 \mathrm{~g}$ chitosan produced from crab shell waste is added to a solution of acetic acid $1 \%(100 \mathrm{~mL})$, then sonicated until the chitosan solution is homogeneous $(\mathrm{t}=2 \mathrm{~h})$. Different place, $1 \mathrm{~g}$ of CNT is added with $100 \mathrm{ml}$ of distilled water, sonicated until the mixture is homogeneous $(\mathrm{t}=2 \mathrm{~h})$. Furthermore, both are mixed, sonicated $(t=4 \mathrm{~h})$, then added a solution of glutaraldehyde $2.5 \%(3.5 \mathrm{~mL})$ while sonication process is still running, dried. The results obtained, characterized by using FTIR, XRD and SEM.

\subsection{Applications MWCNT/Chitosan Nanocomposite as Adsorbent in Liquid Waste Gold Mine}

Prepared column chromatography with MWCNT-chitosan nanocomposite. 5 g MWCNT-chitosan nanocomposite taken and put in a chromatography column that has been coated with frits on the 
bottom, and then coated again frits at the top after the nanocomposite is inserted. $25 \mathrm{~mL}$ sample gold mine effluent put into the chromatographic column already containing MWCNT-chitosan nanocomposite adsorbent. Allowed to stand for 5 minutes, then opened the faucet chromatography column and flowed slowly with a flow rate of $5 \mathrm{~mL} / \mathrm{min}$. Then the filtrate obtained was analyzed by ICP-AES. The same treatment was also carried out for the time variation of contact 10, 15, 20 and 25 minutes.

\section{RESUlTS AND DisCUSSION}

\subsection{FTIR Results of MWCNT}

FTIR characterization results with activated carbon after impregnated with metallic $\mathrm{Fe}$ as shown in Figure 1 (a), where the wave number $1390-1300 \mathrm{~cm}^{-1}$ indicates the NO group shown in the wave number $1328.33 \mathrm{~cm}^{-1}$, which means the presence of $\mathrm{N}=\mathrm{O}$ symmetry derived of $\mathrm{Fe}\left(\mathrm{NO}_{3}\right)_{3}$ used in the carbon impregnation. In wave number $1066.78 \mathrm{~cm}^{-1}$ indicates the presence of C-O. It can be caused by the impregnation of $\mathrm{Fe}$ into activated carbon. $=\mathrm{C}-\mathrm{H}$ bending out the field contained in the wave number $795.22 \mathrm{~cm}^{-1}$, and this is evidenced by the appearance of the spectrum at wave number $795 \mathrm{~cm}^{-}$ 1 .

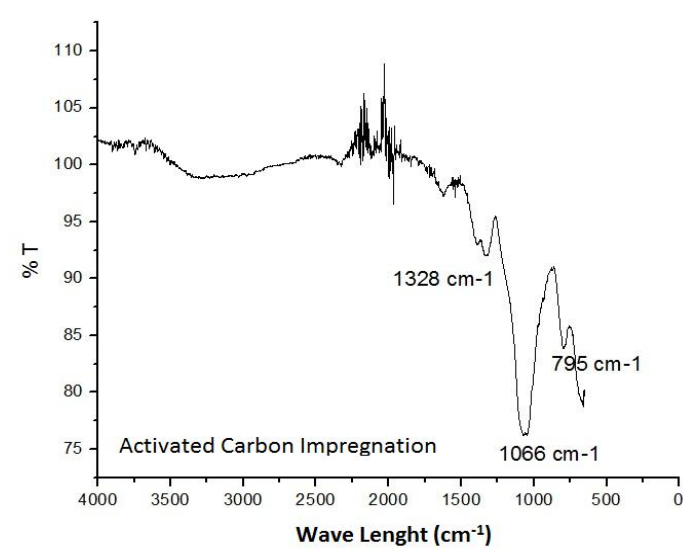

(a)

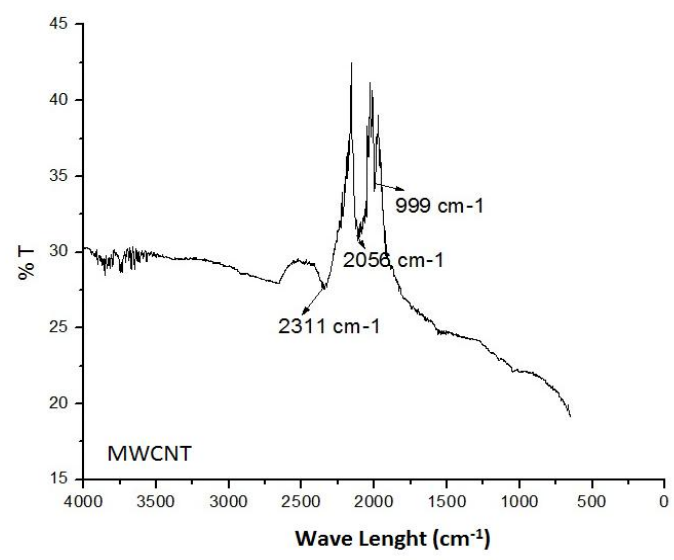

(b)

Figure1. (a) FTIR activated carbon after impregnation with Fe ion (b) MWCNT

Meanwhile, the FTIR results MWCNT as in Figure 1 (b), where in the area visible shift in wavenumber $2311.04 \mathrm{~cm}^{-1}$ indicating absorption at the alkyne compound and reinforced by the weak absorption around wavenumber $2056.15 \mathrm{~cm}^{-1}$ and $1999.81 \mathrm{~cm}^{-1}$.

\subsection{FTIR Results of MWCNT/Chitosan Nanocomposite}

Results of FTIR MWCNT - chitosan nanocomposite composition (1:2) as shown in Figure 2 which shows the vibration stretching $\mathrm{OH}$ experiencing a shift in the spectrum of $3211.08 \mathrm{~cm}^{-1}$ and is reinforced by the appearance of absorption sharply on the spectrum of $1020.09 \mathrm{~cm}^{-1}$ indicating the presence of groups carbonyl CO. The appearance of weak absorption that the shifting of the spectrum in $2878.30 \mathrm{~cm}^{-1}$ showing - $\mathrm{CH}$ aliphatic reinforced by the appearance of a sharp absorption at 1403.85 $\mathrm{cm}^{-1}$ and $1322.02 \mathrm{~cm}^{-1}$ indicates the $\mathrm{CH}_{2}$ and $\mathrm{CH}_{3}$. The shift occurred in the $\mathrm{C}=\mathrm{C}$ bonds with a sharp appearance and the absorption spectrum of moderate intensity at $1622.66 \mathrm{~cm}^{-1}$ and $1542.41 \mathrm{~cm}^{-1}$.

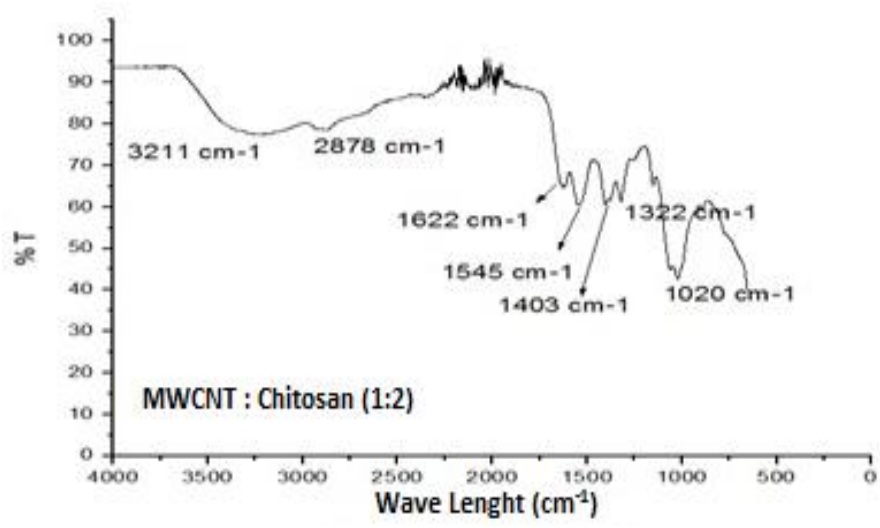

Figure2. FT IR MWCNT/Chitosan Nanocomposite 


\subsection{XRD Results of MWCNT/Chitosan Nanocomposite}

Based on the XRD data by comparison MWCNT/chitosan nanocomposite composition (1:2) showed peaks increasingly diverse where the MWCNT combined with chitosan. and it produces a peak that appears on $44,52^{\circ}, 64,84^{\circ}, 38,29^{\circ}$, it indicates that the difference of form MWCNT and chitosan after forming MWCNT/chitosan nanocomposite. This indicates that the MWCNT shifted peak as well as the peak of chitosan. The results of X-ray diffraction pattern for MWCNT/chitosan nanocomposite particles as in Figure 3 below.

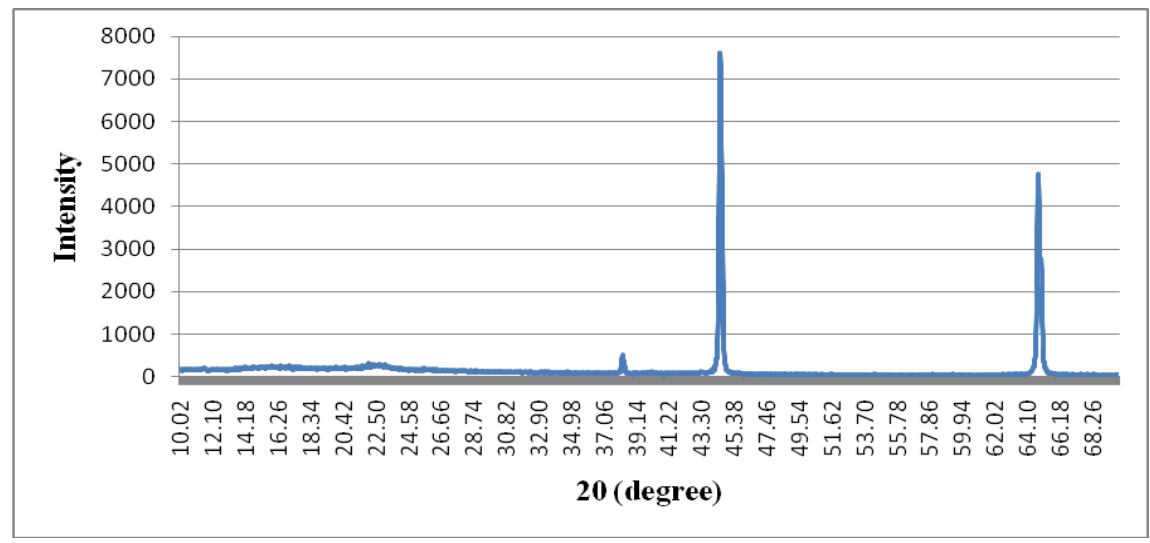

Figure3. XRD Pattern-Chitosan CNT Nanocomposite

Based on the calculation of particle size XRD for MWCNT / chitosan nanocomposite, it is known that the MWCNT / chitosan nanocomposite has a particle size of $96.20007 \mathrm{~nm}$ minimum and maximum of 229.5385 with an average of $131.0585 \mathrm{~nm}$.

\subsection{SEM Results of MWCNT and MWCNT-Chitosan Nanocomposite}

Characterization by SEM performed to show the structure of the surface of the MWCNT, Chitosan, MWCNT-chitosan nanocomposite with a magnification of 2,000 times.

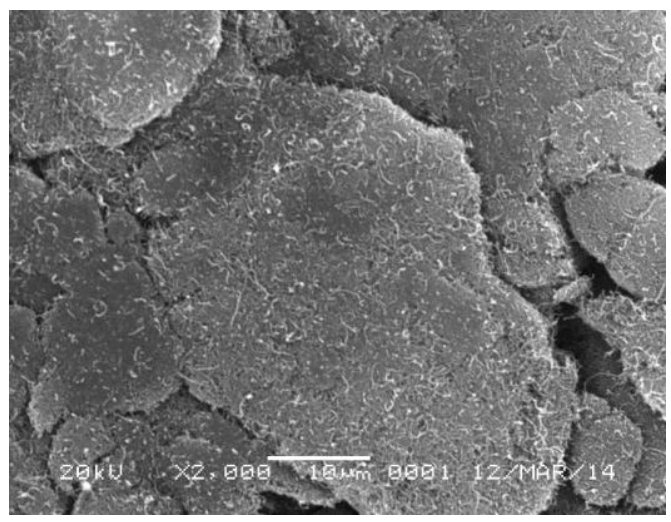

(a)

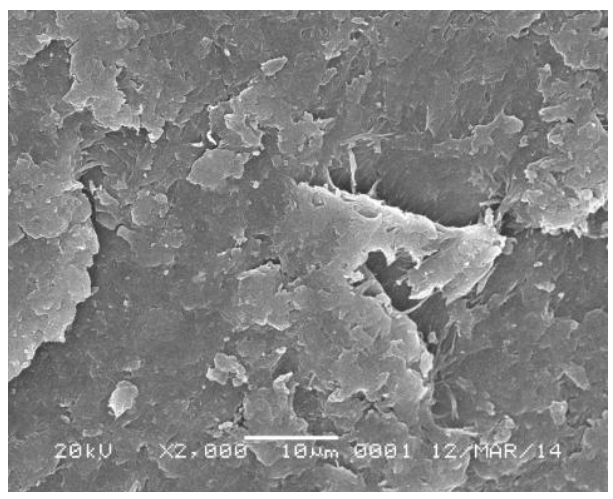

(b)

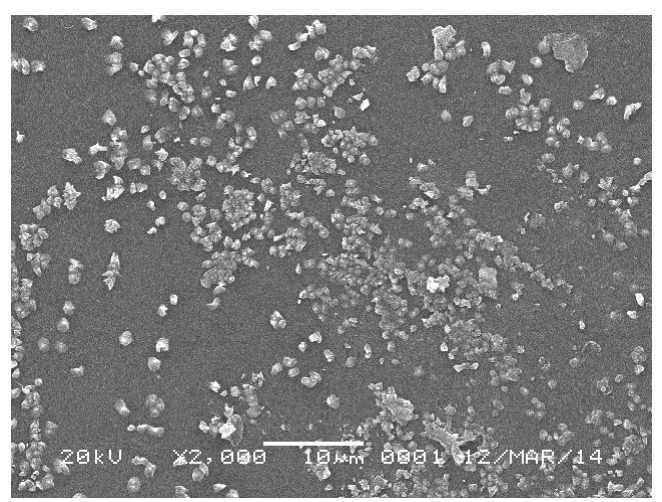

(c)

Figure4. (a) MWCNT (b) Chitosan (c) MWCNT/ChitosanNanocomposite 
SEM results on the MWCNT as Figure 4 (a) shows that the MWCNT-shaped tubes are nano-sized, where sightings of long pipes that form a homogeneous yet exist in the form of straight and curved. SEM results on chitosan as Figure 4 (b) shows morphological differences with the other pictures in which the visible surface is more smooth and the particles are much larger. Meanwhile, the results of SEM MWCNT-chitosan nanocomposite as Figure 4 (c) shows that the surface structure and pore pore clear and visible pipes were coated with chitosan.

\subsection{The Results of ICP-AES For Hg Ion On Liquid Waste Gold Mine Samples}

Ion absorption $\mathrm{Hg}$ in the sample liquid waste gold mines use several adsorbents include: activated carbon, CNT, chitosan, CNT-chitosan nanocomposite (1: 1), (1:2), and (1:3) with a flow rate remains $5 \mathrm{~mL} / \mathrm{min}$ and a contact time of 15 minutes. Percentage absorption of the ion $\mathrm{Hg}$ adsorbent can be determined by comparing the concentrations of ions $\mathrm{Hg}$ before and after using adsorbents. Where the initial concentration of ions in the liquid waste $\mathrm{Hg}$ gold mine that is equal to $3.0352 \mathrm{mg} / \mathrm{L}$.

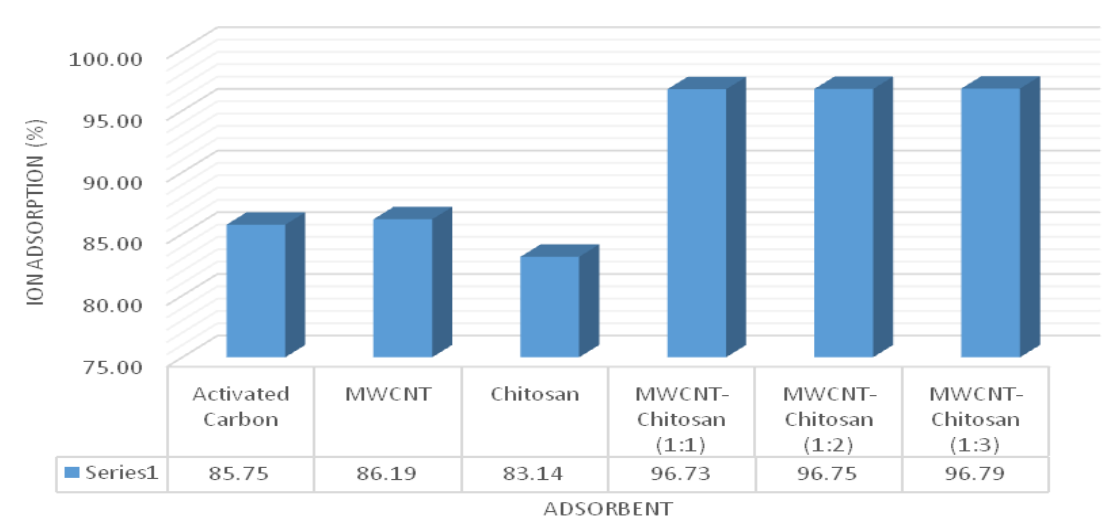

Figure5. Graph of the relationship between the percentage of $\mathrm{Hg}$ ion absorption with variations adsorbent

Based on Figure 5 it was found that MWCNT have far better absorption of active carbon. According to Zhang (2006) MWCNT has advantages such as low resistivity, high conductivity, and high stability.From some unknown adsorbent used for adsorbent MWCNT / chitosan nanocomposite has the percentage of absorption is much better that the average absorption is above $95 \%$. Differences in the composition of the MWCT : Chitosan ( $1: 1)$, MWCT : Chitosan ( $1: 2)$, and MWCT : Chitosan $(1: 3)$ shows that the three variations of these compositions was no significant difference in the absorption of metal ions $\mathrm{Hg}$.

So based on that data, the analysis continued on the adsorbent MWCNT-chitosan nanocomposite (1:2) with a flow time fixed at $5 \mathrm{~mL} / \mathrm{min}$ but the contact time between the adsorbent with a sample of liquid waste goldmine varied are 5, 10, 15, 20 and 25 minutes.

\subsection{Calculation of $\mathrm{Hg}$ Ion Absorption In Liquid Waste Gold Mine Samples Using Adsorbent MWCNT / chitosan nanocomposite (1: 2)}

$\mathrm{Hg}$ ion absorption in the sample liquid waste gold mining is done using adsorbents MWCNT/chitosan nanocomposite $(1: 2)$ with a fixed flow at $5 \mathrm{~mL} / \mathrm{min}$, but the contact time was varied at $5,10,15,20$ and 25 minutes. Figure 8 presents the data graph of $\mathrm{Hg}$ ion concentration after absorption with contact time, and Figure 9 presents the data graph of the percentage of $\mathrm{Hg}$ ion absorption with contact time.

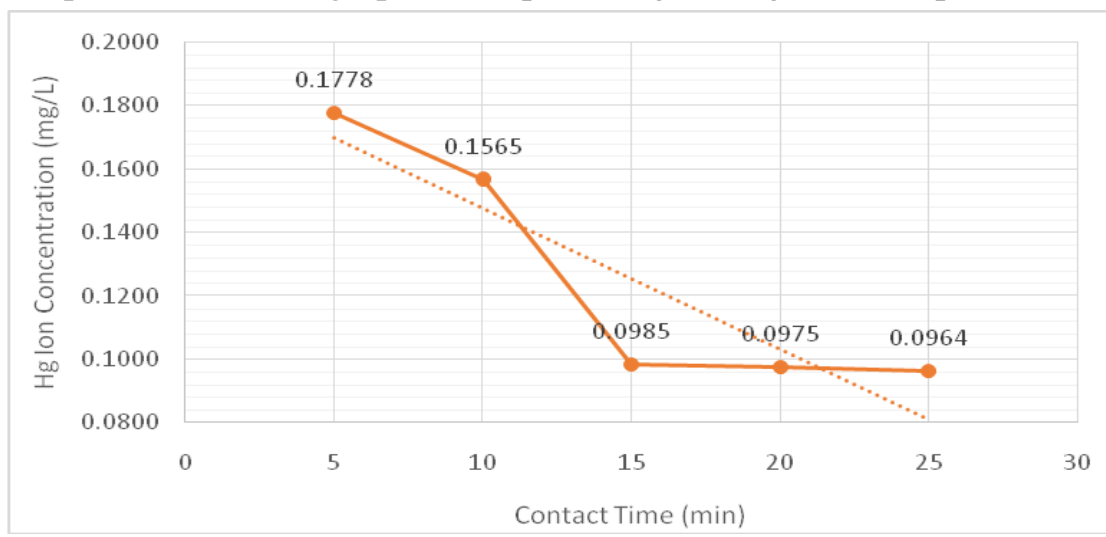

Figure8. Graph of the relationship between the concentration of ions $\mathrm{Hg}$ with a contact time 


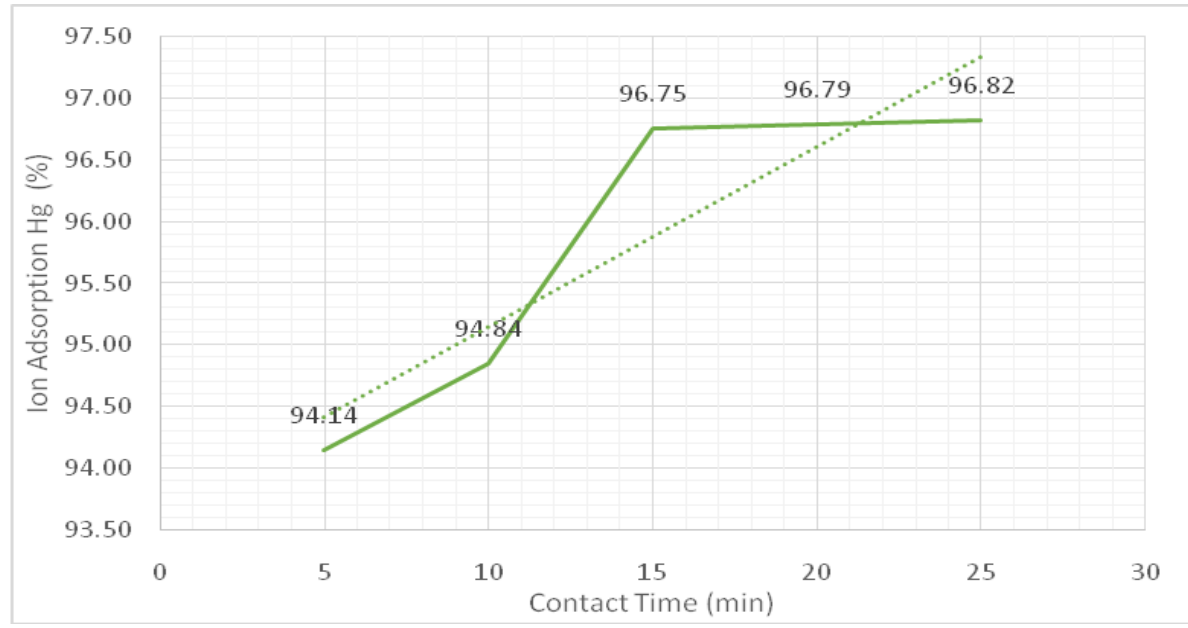

Figure9. Graph of the relationship betweenthe percentage of $\mathrm{Hg}$ ion absorption with contact time

The use of CNT-chitosan nanocomposite adsorbent (1: 2) with a contact time of 15, 20 and 25 minutes, the result $\mathrm{Hg}$ ion absorption maximum at around $96 \%$, with the maximum results at 25 minutes contact time at $96.82 \%$ by the end of the ion concentration of $0.0964 \mathrm{mg} \mathrm{Hg} / \mathrm{L}$. The final concentration of ions $\mathrm{Hg}$ at 25 minutes contact time that is equal to $0.0964 \mathrm{mg} / \mathrm{L}$. This concentration is considered not meet the quality standard limits for drinking water that is equal to the smaller of $0.001 \mathrm{mg} / \mathrm{L}$. The difference amounted to $0.0965 \mathrm{mg} / \mathrm{L}$ can still be resolved by re-screening using these adsorbents are already free of metal ions.

\section{Conclusion}

Based on these results, it can be concluded that the MWCNT/Chitosan nanocomposite can be produced by mixing the MWCNT from oil palm shells and Chitosan with a composition ratio MWCNT/Chitosan (1:2) via sonication process by adding glutaraldehyde $2.5 \%$ as a crosslinking. FTIR results showed a shift in the $\mathrm{C}=\mathrm{C}$ bonds with a sharp appearance and the absorption spectrum of moderate intensity at $1622.66 \mathrm{~cm}^{-1}$ and $1542.41 \mathrm{~cm}^{-1}$. XRD test results showed that the MWCNT/Chitosan nanocomposite has an average particle size of $131.0585 \mathrm{~nm}$. SEM results show that the morphology of the MWCNT produced long tubular. Applications MWCNT/Chitosan nanocomposite as an adsorbent to absorb metal ions $\mathrm{Hg}$ from liquid waste gold mine of $96.82 \%$ with a contact time of 25 minutes, flow rate of $5 \mathrm{~mL} / \mathrm{min}$ with a temperature fixed at room temperature.

\section{REFERENCES}

[1] Carson, L., et.al., Synthesis And Characterization of Chitosan - Carbon Nanotube Composites, Journal Institute of Health, NIH Public Access, (2009).

[2] Najma, Pertumbuhan Nanokarbon Menggunakan Karbon Aktif Dari Limbah Kulit Pisang Dengan Metode Pirolisis Sederhana dan Dekomposisi Metana, Chemical Engineering Departement, Universitas Indonesia, Jakarta, Indonesia, (2012).

[3] Nur, A., et.al., Carbon Nanotube Synthesis For Hydrogen Storage : A Review, International Symposium Nanotechnology Catalyst, Serpong, Indonesia, (2007).

[4] Salam, M.A., et.al., Preparation and Characterization of Multi-Walled Carbon Nanotubes/ Chitosan Nano composites and Its Application For The Removal of Heavy Metal From Aqueous Solution, Journal of Alloys and Compounds, (2011).

[5] Shieh, Y.T., et.al., Electrocatalytic Behavior and $\mathrm{H}_{2} \mathrm{O}_{2}$ Detection of Carbon Nanotube/ Chitosan Nanocomposites Prepared Via Different Acidic Aqueous Solutions, International Journal Electrochem, Sci., (2012).

[6] Sivakumar, V.M., et.al., Optimized Parameters For Carbon Nanotubes Synthesis Over Fe dan Ni Catalyst Via Methane CVD,Rev. Adv. Mater, (2011).

[7] Wiyarsi , A., Priyambodo, E., Pengaruh Konsentrasi Kitosan Dari Cangkang Udang Terhadap Efisiensi Penyerapan Logam Berat, Uiversitas Negeri Yogyakarta, Indonesia, (2011). 
[8] Tippawan, S., et.al. The Effect Of Temperature On The Growth of Carbon Nanotubes By Catalytic Chemical Vapor Deposito. Department of Physics. Ubon Ratchathani.. Thailand,. (2005).

[9] Zhu, H.Y., et.al., Preparation, Characterization and Adsorption Properties of Chitosan Modified Magnetic Graphitized Multi-Walled Carbon Nanotubes Forhighly Effective Removal Of A Carcinogenic Dye From Aqueous Solution, Applied Surfec Science, (2013).

[10] Zurairah, M.S., et.al., Preparation And Characterization Carbon Nanotubes - Chitosan Nanocomposite By Using Oil Palm Shell And Horseshoe Crab Shell, International Journal of Advanced Research in Chemical Science, Volume II, Issue I, (2015).

\section{AUTHORS' BIOGRAPHY}

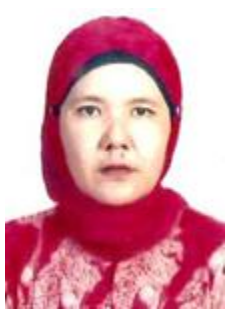

Dr. Masdania Zurairah Siregar, S.Si, M.Si, was born on February 8, 1964 in Padang Sidempuan, Indonesia. The author-1 completed undergraduate program (S-1) chemistry at the University of Sumatera Utara, and then also completed post-graduate program (S-2) chemistry at the University of umatera Utara and Doctoral Program (S-3) chemistry at the University of Sumatera Utara, and now also remains active as a lecturer inFaculty of Engineering, University of Al-Azhar Medan.

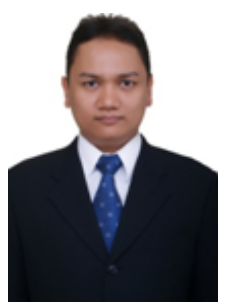

Ahmad Hafizullah Ritonga, S.Si, M.Si, was born on May 13, 1981 in Medan, Indonesia. The author-2 completed undergraduate program (S-1) chemistry at the University of Sumatera Utara, and then also completed post-graduate program (S-2) chemistry at the University of Sumatera Utara. The author-2 active as a lecturer inFaculty of Engineering, University of Al-Azhar Medan. 